\title{
Hospital utilization and disposition among patients with malignant bowel obstruction: a population-based comparison of surgical to medical management
}

\author{
Sarah B. Bateni ${ }^{1}$, Alicia A. Gingrich ${ }^{1}$, Susan L. Stewart ${ }^{2}$, Frederick J. Meyers ${ }^{3}$, Richard J. Bold ${ }^{1}$
}

and Robert J. Canter ${ }^{1 *}$ (D)

\begin{abstract}
Background: Malignant bowel obstruction (MBO) is often a terminal event in end-stage cancer patients. The decision to intervene surgically is complex, given the risk of harm in patients with a limited lifespan. Therefore, we sought to compare clinically meaningful outcomes in MBO patients treated with surgical versus medical management using population-based data.

Methods: We performed a retrospective analysis of hospitalized patients with MBO from 2006 to 2010 using the California Office of Statewide Health Planning and Development dataset. Hospital-free days (HFDs) at 30-, 90-, and 180days were calculated accounting for all hospitalization, emergency department visit, and skilled nursing facility lengths of stay. Adjusted regression models were used to compare HFDs, disposition, complications, in-hospital death, and survival for surgical versus medical MBO cohorts, using inverse probability of treatment weighting with propensity scores.

Results: Of 4576 MBO patients, 3421 (74.8\%) were treated medically and 1155 (25.2\%) were treated surgically. Surgical patients had higher rates of complications $(44.0 \%$ vs. $21.3 \%, p<0.0001)$ and in-hospital death $(9.5 \%$ vs. $3.9 \%, \mathrm{p}<0.0001)$ with lower rates of disposition to home $(76.3 \%$ vs. $89.8 \%, p<0.0001)$. Surgical patients had fewer 30 - and 90 -day HFDs compared to medical patients $(p<0.01)$. However, at 180-days, there were no differences in HFDs between treatment groups. There was no difference in overall survival between surgical and medical patients (median 6.5 vs. 6.4 months).

Conclusion: In this population-based analysis, medical management was associated with less hospital utilization at 30- and 90-days, fewer in-hospital deaths, and more frequent discharges to home. These data underscore the potential benefits of medical management for MBO patients at the end-of-life.
\end{abstract}

Keywords: Malignant bowel obstruction, Bowel obstruction, Surgery, Disposition, Hospital utilization, Palliative surgery

\section{Background}

Malignant bowel obstruction (MBO) is common among patients with disseminated malignancy with rates as high as $28 \%$ for gastrointestinal and $51 \%$ for gynecologic cancers [1]. Moreover, MBO is often a pre-terminal event with median survival ranging from 1 to 9 months after diagnosis [1-6]. Therefore, a key objective of $\mathrm{MBO}$

\footnotetext{
* Correspondence: rjcanter@ucdavis.edu

${ }^{1}$ Division of Surgical Oncology, UC Davis Cancer Center, 4501 X Street, Suite 3010, Sacramento, CA 95817, USA

Full list of author information is available at the end of the article
}

management is to achieve optimal palliation with a focus on relieving debilitating symptoms and optimizing patient quality of life. Previous studies have shown that there is significant variation in the approach to $\mathrm{MBO}$, and the decision to treat with either medical or surgical management is complex $[1,4,6]$. Surgical intervention in advanced cancer patients is associated with high risks of morbidity with potential to adversely impact patient quality of life [7-10]. Prior studies have shown serious complication rates as high as $44 \%$ and readmission rates as high as $74 \%$ among MBO patients treated with palliative surgery [6]. Despite

(c) The Author(s). 2018 Open Access This article is distributed under the terms of the Creative Commons Attribution 4.0 International License (http://creativecommons.org/licenses/by/4.0/), which permits unrestricted use, distribution, and reproduction in any medium, provided you give appropriate credit to the original author(s) and the source, provide a link to the Creative Commons license, and indicate if changes were made. The Creative Commons Public Domain Dedication waiver (http://creativecommons.org/publicdomain/zero/1.0/) applies to the data made available in this article, unless otherwise stated. 
these findings, it continues to remain unclear the optimal palliative treatment for $\mathrm{MBO}$ since surgery can offer the potential for durable symptom palliation, including obstruction resolution and resumption of diet $[1,6,11,12]$.

Although treatment guidelines have been formulated by multidisciplinary physician groups for $\mathrm{MBO}$, the decision to proceed with medical versus surgical management is variable, as it is often determined based the surgeon's own clinical experience and/or the patient's preferences and goals-of-care [13-15]. The National Comprehensive Cancer Network guidelines recommend that the management of MBO be largely guided by patients' life-expectancy [13]. Surgical and/or procedural management should be considered in patients with several months to years of life remaining, while medical management is recommended for those with only months to weeks of life remaining and for poor surgical candidates based on known risk factors including ascites, extensive peritoneal carcinomatosis, multiple sites of obstruction, and poor functional status. Despite such expert consensus guidelines, $\mathrm{MBO}$ treatment remains variable as such guidelines have not been well disseminated, thereby allowing physicians', surgeons' and patients' preferences to direct treatment decisions for $\mathrm{MBO}$.

To date, there have been few population-based analyses comparing outcomes of surgical and medical treatment of MBO $[1,6]$. The majority of studies have consisted of retrospective, single institution analyses using patient cohorts as small as 22 individuals $[1,16]$. Notable exceptions have analyzed outcomes among ovarian, pancreatic, and colorectal cancer patients in the Medicare population, thereby limiting the generalizability of the findings to the elderly population with only those specific cancer diagnoses [3-5]. Since MBO frequently occurs among patients younger than 65 years of age and in the setting of other malignancies such as gastric and non-ovarian genitourinary cancers, we sought to perform a population-based analysis encompassing a more heterogeneous patient cohort $[6,17]$. Furthermore, the vast majority of prior $\mathrm{MBO}$ studies principally focused on survival as the outcome of interest and have failed to evaluate other important outcomes related to quality of life and resource utilization. As such, we sought to analyze additional key metrics, including place of death and hospital utilization, which are largely absent in current $\mathrm{MBO}$ research and palliative surgery research overall $[3,5,18]$.

Therefore, the purpose of this study was to address these current gaps in literature by performing a population-based analysis comparing clinically meaningful end-of-life outcomes for MBO patients treated with medical versus surgical management. We specifically sought to compare in-hospital deaths, disposition to home, and hospital-free days (HFDs). HFDs is composite endpoint which incorporates the length of stay (LOS) of the index hospitalization, readmissions, and skilled nursing facility visits and survival. We specifically chose this measure as it is a patient-centered quality metric that reflects both resource utilization and end-stage cancer patients' goals of avoiding prolonged and repeated hospitalizations near the end of life [19-21].

\section{Methods}

We performed a retrospective analysis of hospitalized patients with MBO from 2006 to 2010 at all California licensed hospitals using the Office of Statewide Health Planning and Development (OSHPD) death linked dataset. The OSHPD dataset consists of patient discharge (PDD), emergency department (EDD), and linked-death files from the California Department of Public Health vital statistic records. PDD consists of all patient records for acute hospitalizations and skilled nursing facility (SNF) visits from California licensed hospitals and SNFs. EDD consists of all emergency department visits patient records from California licensed hospitals. OSHPD has been previously used as the primary data source for various studies

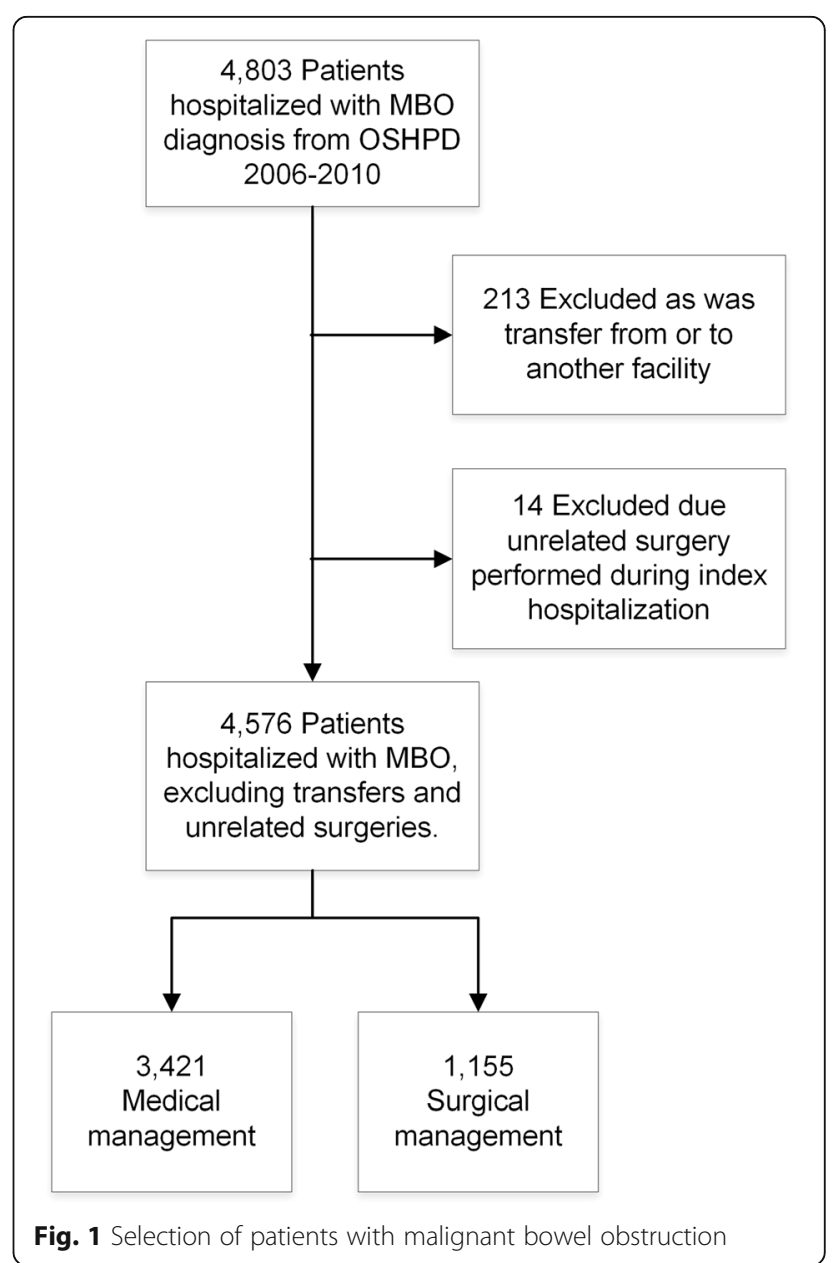


investigating healthcare utilization and patient outcomes in general surgery and surgical oncology [22-25]. The research protocol was approved by the University of California, Davis Institutional Review Board and the California Health and Human Services Agency Committee for the Protection of Human Subjects.

We identified 4803 patients admitted to an acute care hospital with the diagnosis of MBO from 2006 to 2010 (Fig. 1). MBO was defined using the principal diagnosis of bowel obstruction and a secondary diagnosis of intra-abdominal metastatic cancer (indicative of stage IV cancer) based on International Classification of Diseases 9th edition (ICD-9) codes from OSHPD (see Additional file 1: Table S1) $[4,26]$. We did not include patients with a secondary diagnosis of bowel obstruction to prevent inclusion of patients who underwent an unrelated surgery and then experienced a post-operative bowel obstruction. To ensure complete record of length of hospitalization, we excluded 213 patients who were transferred from or to an outside hospital. Fourteen patients who had an operation performed not standard for MBO such as cholecystectomy, lung resection, and intra-abdominal biopsy were also excluded to ensure patients were appropriately assigned to medical and surgical groups. The final cohort consisted of 4576 patients with MBO. Surgical patients were defined as patients who underwent one or more of the following operations from ICD-9 procedure codes (see supplement) during the first $\mathrm{MBO}$ hospitalization: exploratory laparotomy, adhesiolysis, small or large bowel resection, enterostomy, colostomy, gastrointestinal or enteric bypass, and open gastrostomy. Due to the small number of procedural interventions alone (94 percutaneous gastrostomy tubes and 10 enteric stents), we chose to include these patients in the medical management cohort, as these procedural interventions do not require general anesthesia and are not associated with the same recovery time as surgical management for MBO.

Patient covariates assessed included demographics (age, gender, race, ethnicity), primary cancer diagnosis, medical comorbidities including diagnosis of ascites, and do not resuscitate (DNR) status. The Elixhauser comorbidity index, a well-established and previously validated measure of readmission and mortality risk based on 29 medical comorbidities, was used to assess patient comorbidities [27-30].

Table 1 Patient demographics and clinical characteristics

\begin{tabular}{|c|c|c|c|c|c|}
\hline & \multicolumn{2}{|c|}{ Medical Management $N=3421$} & \multicolumn{2}{|c|}{ Surgical Management $N=1155$} & \multirow[t]{2}{*}{$P$ value } \\
\hline & N or Mean & $\%$ or SD & $\mathrm{N}$ or Mean & $\%$ or SD & \\
\hline Age & 63.2 & 13.6 & 64.6 & 13.7 & 0.002 \\
\hline Male & 1186 & $34.7 \%$ & 414 & $35.8 \%$ & 0.47 \\
\hline \multicolumn{6}{|l|}{ Race } \\
\hline Caucasian & 2132 & $62.3 \%$ & 777 & $67.3 \%$ & 0.007 \\
\hline Black & 230 & $6.7 \%$ & 79 & $6.8 \%$ & \\
\hline Asian/Pacific Islander & 394 & $11.5 \%$ & 129 & $11.2 \%$ & \\
\hline Hispanic & 587 & $17.1 \%$ & 149 & $12.9 \%$ & \\
\hline Other/Unknown & 78 & $2.3 \%$ & 21 & $1.8 \%$ & \\
\hline Elixhauser Comorbidity Index Score & 19.3 & 7.9 & 21.9 & 9.1 & $<0.0001$ \\
\hline Ascites & 445 & $13.0 \%$ & 164 & $14.2 \%$ & 0.30 \\
\hline DNR Status & 443 & $13.0 \%$ & 128 & $11.1 \%$ & 0.10 \\
\hline \multicolumn{6}{|l|}{ Primary Cancer Diagnosis } \\
\hline Colorectal & 1046 & $30.6 \%$ & 345 & $29.9 \%$ & 0.65 \\
\hline Pancreatic & 164 & $4.8 \%$ & 57 & $4.9 \%$ & 0.85 \\
\hline Ovarian & 840 & $24.6 \%$ & 220 & $19.1 \%$ & 0.0001 \\
\hline Foregut and Small Bowel & 213 & $6.2 \%$ & 72 & $6.2 \%$ & 0.99 \\
\hline Hepatobiliary & 78 & $2.3 \%$ & 19 & $1.7 \%$ & 0.20 \\
\hline Lung/Mediastinal & 90 & $2.6 \%$ & 38 & $3.3 \%$ & 0.24 \\
\hline Nonovarian Urogyn & 395 & $11.6 \%$ & 134 & $11.6 \%$ & 0.96 \\
\hline Other & 879 & $25.7 \%$ & 218 & $18.9 \%$ & $<0.0001$ \\
\hline Unknown & 509 & $14.9 \%$ & 228 & $19.7 \%$ & 0.0001 \\
\hline Multiple Cancer Diagnoses & 791 & $23.1 \%$ & 180 & $15.6 \%$ & $<0.0001$ \\
\hline
\end{tabular}

$S D$ standard deviation, Urogyn urogynecological 
The primary outcomes were disposition to home, in-hospital deaths and HFDs. HFDs at 30-, 90-, and 180-days were calculated as the summation of the LOS for the index $\mathrm{MBO}$ hospitalization, readmissions, emergency department visits, and skilled nursing facility stays subtracted from 30, 90, 180 or days from diagnosis to death if earlier than the corresponding interval [21, 31]. For example, a patients who is initially hospitalized for 3 days and discharged home only to die 5 days later would have HFDs of 5 at 30-, 90- and 180-days. A patient who is initially hospitalized for 14 days, discharged home for 2 days, readmitted and hospitalized for 20 days, and subsequently discharged home without any further readmissions, dying 1 year later, would have HFDs of 2 at 30-days, 56 at 90-days, 148 at 180-days.

Secondary endpoints were complications within 30-days of hospitalization, readmissions within 7- and 30-days of discharge, re-obstruction within 1 year from first diagnosis (based on ICD-9 codes for emergency department visits and readmissions), time from discharge to readmission and re-obstruction, and overall survival. Thirty-day complications were identified from ICD-9 codes and included pulmonary failure, pneumonia, cardiac complications, acute renal failure, pulmonary embolus, deep vein thrombosis, hemorrhage, shock, and wound complications [32-34]. Survival was measured from the first admission date for $\mathrm{MBO}$ to date of death or last date of vital status follow-up.

\section{Statistical analysis}

Patient covariates were presented as means with standard deviations and frequencies with percentages for continuous and categorical variables unless otherwise stated. Chi square and student t-tests assessed differences in baseline covariates and outcomes between groups. Propensity scores estimating the probability of selection into medical or surgical management based on patient demographics (age, race, gender), cancer diagnoses, presence of ascites, Elixhuaser comorbidity index score, and DNR status were created. Inverse probability of treatment weighting (IPTW) based on these propensity scores was used in the analysis of our primary and secondary endpoints to address selection bias for MBO treatment $[35,36]$. Covariates balance was determined to be appropriate between groups with IPTW using standardized differences.

Multinomial logistic regression with IPTW was performed to compare risk of returning home versus in-hospital death or discharge to facility for surgical and medical groups. HFDs were observed to have a bimodal distribution and, consequently, appropriate for a logistic regression model. We therefore categorized HFDs as less than or equal to/greater than the median, which was 20 days for 30-day HFDs, 70 days for 90-day HFDs, and 133 days for 180-day HFDs. IPTW logistic regression was performed to evaluate differences in HFDs between groups and identify predictors of fewer HFDs. Sensitivity analysis was performed to determine if there were differences in HFDs between groups when including only hospitalizations versus including all hospitalizations and SNF visits. As there were no statistically significant differences observed, we chose to present results for HFDs including SNF visits.

Logistic regression with IPTW was performed to compare 30-day complications, readmissions, and re-obstruction for medical and surgical patients. Time-to-event analysis for readmissions and re-obstruction was performed using the Fine and Gray competing risk model, accounting for death as a competing event, with IPTW. Linear regression with IPTW was performed to compare hospital LOS for the index admission. Log transformation of LOS was performed to achieve normality in the linear regression model. Log-rank test with and without IPTW was used to compare overall survival between treatment groups.

\section{Results}

Of the 4576 patients hospitalized with MBO, 3421 (74.8\%) were treated with medical management and 1155 (25.2\%) were treated with surgery with significant differences in age, race, comorbidities, and cancer diagnoses between groups (Table 1). Those treated with surgery were slightly older (64.6 vs. 63.2 years old, $p=0.002)$, more frequently Caucasian (67.3\% vs $62.3 \%, p=0.007)$, with greater Elixhauser comorbidity scores (21.9 vs. 19.3, $p<0.0001)$, and were less frequently diagnosed with ovarian cancer $(19.1 \%$ vs. $24.6 \%, p=0.0001)$ and multiple cancer diagnoses $(15.6 \%$ vs. $23.1 \%, p<0.0001)$. There were

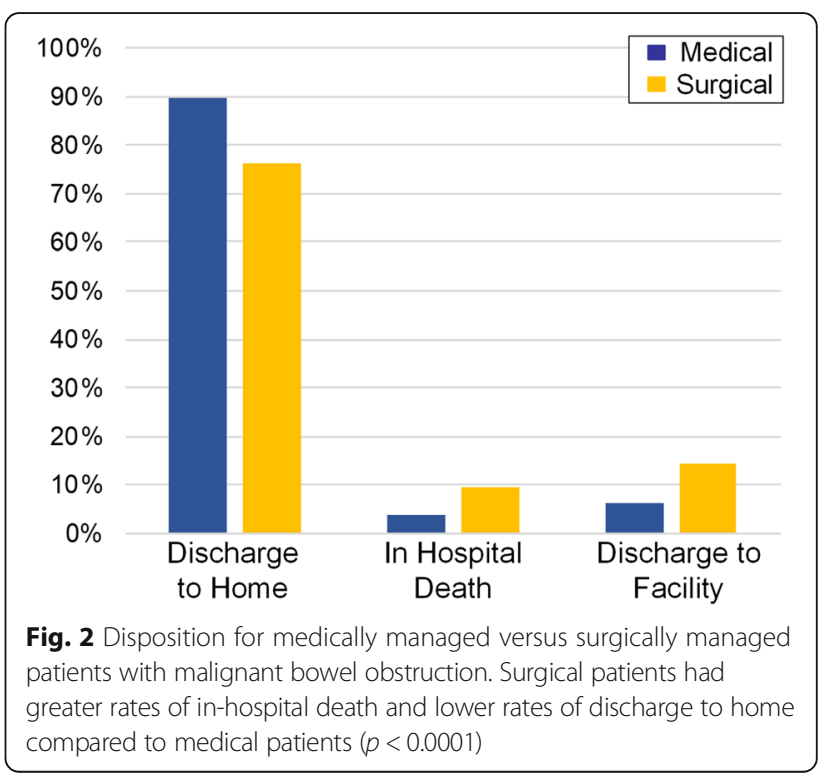


differences in rates of surgical management by year with $27.5 \%$ of patients undergoing surgery in 2006, $29.4 \%$ in $2007,23.0 \%$ in $2008,25.7 \%$ in 2009 , and $21.4 \%$ in $2010(p=0.0005)$.

As shown in Fig. 2, surgical patients had greater rates of in-hospital death $(9.5 \%$ vs. $3.9 \%, p<0.0001)$ and lower rates of discharge to home $(76.3 \%$ vs. $89.8 \%, \mathrm{p}<0.0001)$ in our unweighted analysis. In the IPTW model, surgical patients had greater odds of in-hospital death (OR 2.28,
95\%CI 1.73-3.00, $\mathrm{p}<0.0001)$ and disposition to a facility (OR 2.34, 95\%CI 1.86-2.94, $p<0.0001$ ) compared to medical patients (Table 2). Additional predictors of both in-hospital death and disposition to facilities included Elixhauser comorbidity scores and DNR status ( $p<0.0001$ all).

Rates of 30-, 90- and 180-day HFDs greater than each respective median in the unweighted analyses are shown in Fig. 3. Surgical patients had greater odds of fewer HFDs (HFDs below the respective median) at 30-days

Table 2 Univariate (Model 1) and multivariate (Model 2) inverse probability to treatment weighted regression models for patient disposition from the index hospitalization for malignant bowel obstruction

\begin{tabular}{|c|c|c|c|c|c|c|c|c|}
\hline & \multicolumn{4}{|c|}{ In-Hospital Deatha } & \multicolumn{4}{|c|}{ Disposition to a Facility ${ }^{a}$} \\
\hline & \multirow[t]{2}{*}{ OR } & \multicolumn{2}{|l|}{$95 \% \mathrm{Cl}$} & \multirow[t]{2}{*}{$P$ value } & \multirow[t]{2}{*}{ OR } & \multicolumn{2}{|c|}{$95 \% \mathrm{Cl}$} & \multirow[t]{2}{*}{$P$ value } \\
\hline \multicolumn{5}{|l|}{ Model 1} & & & & \\
\hline \multicolumn{9}{|l|}{ Treatment } \\
\hline \multicolumn{9}{|l|}{ Medical (ref) } \\
\hline Surgery & 2.28 & 1.73 & 3.00 & $<0.0001$ & 2.34 & 1.86 & 2.94 & $<0.0001$ \\
\hline \multicolumn{9}{|l|}{ Model 2} \\
\hline \multicolumn{9}{|l|}{ Treatment } \\
\hline \multicolumn{9}{|l|}{ Medical (ref) } \\
\hline Surgery & 2.68 & 1.99 & 3.62 & $<0.0001$ & 2.65 & 2.09 & 3.36 & $<0.0001$ \\
\hline Age & 1.03 & 1.02 & 1.05 & $<0.0001$ & 1.06 & 1.04 & 1.07 & $<0.0001$ \\
\hline \multicolumn{9}{|l|}{ Gender } \\
\hline \multicolumn{9}{|l|}{ Female (ref) } \\
\hline Male & 1.61 & 1.13 & 2.28 & 0.01 & 0.99 & 0.73 & 1.34 & 0.95 \\
\hline \multicolumn{9}{|l|}{ Race/Ethnicity } \\
\hline \multicolumn{9}{|l|}{ Caucasian (ref) } \\
\hline Asian/Pacific Islander & 1.07 & 0.63 & 1.82 & 0.80 & 1.17 & 0.75 & 1.82 & 0.49 \\
\hline Black & 1.12 & 0.59 & 2.13 & 0.74 & 1.89 & 1.18 & 3.02 & 0.01 \\
\hline Hispanic & 1.33 & 0.82 & 2.16 & 0.24 & 1.15 & 0.74 & 1.79 & 0.53 \\
\hline Other/Unknown & 0.87 & 0.30 & 2.49 & 0.79 & 0.69 & 0.23 & 2.07 & 0.51 \\
\hline Elixhauser Comorbidity & 1.07 & 1.05 & 1.09 & $<0.0001$ & 1.04 & 1.02 & 1.05 & $<0.0001$ \\
\hline DNR Order & 4.57 & 3.12 & 6.70 & $<0.0001$ & 2.66 & 1.86 & 3.81 & $<0.0001$ \\
\hline Ascites & 1.54 & 1.02 & 2.33 & 0.04 & 1.13 & 0.79 & 1.63 & 0.50 \\
\hline \multicolumn{9}{|l|}{ Cancer Diagnosis } \\
\hline \multicolumn{9}{|l|}{ Colorectal (ref) } \\
\hline Ovarian & 0.43 & 0.20 & 0.90 & 0.02 & 0.79 & 0.48 & 1.29 & 0.34 \\
\hline Pancreatic & 0.81 & 0.36 & 1.84 & 0.62 & 0.54 & 0.23 & 1.25 & 0.15 \\
\hline Hepatobiliary & 0.13 & 0.01 & 1.22 & 0.07 & 0.61 & 0.13 & 2.78 & 0.52 \\
\hline Foregut \& small bowel & 2.09 & 1.08 & 4.04 & 0.03 & 1.33 & 0.64 & 2.76 & 0.44 \\
\hline Nonovarian Urogyn & 1.02 & 0.56 & 1.86 & 0.95 & 0.76 & 0.43 & 1.34 & 0.34 \\
\hline Lung/Mediastinal & 2.60 & 1.14 & 5.92 & 0.02 & 0.69 & 0.27 & 1.76 & 0.44 \\
\hline Other & 0.97 & 0.44 & 2.13 & 0.95 & 1.53 & 0.95 & 2.45 & 0.08 \\
\hline Unknown & 1.02 & 0.62 & 1.70 & 0.95 & 0.80 & 0.54 & 1.19 & 0.26 \\
\hline Multiple Diagnoses & 0.82 & 0.48 & 1.38 & 0.45 & 0.96 & 0.63 & 1.47 & 0.85 \\
\hline
\end{tabular}

Cl confidence interval, Ref reference, Urogyn Urogynecological, ${ }^{2}$ Reference is disposition to home in multinomial logistic regression model 


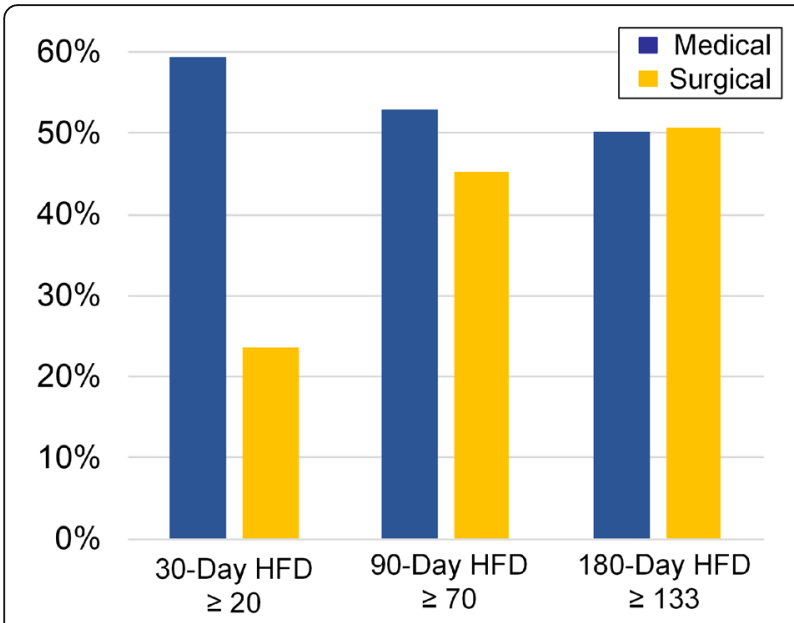

Fig. 3 30-day, 90-day, and 180-day hospital-free days (HFDs) greater than each respective median for medically managed versus surgically managed patients with malignant bowel obstruction. Surgical patients had fewer HFDs at 30 and 90 days compared to medical patients $(p<0.01)$. There was no difference between groups in HFDs at 180 days $(p>0.05)$

(OR 3.98, 95\%CI 3.40-4.67, $p<0.0001$ ) and 90-days (OR 1.24, 95\%CI 1.08-1.42, $p=0.004$ ) compared to medical patients in the IPTW models (Table 3). However, there was no difference in HFDs at 180-days in the IPTW model (OR 0.89, 95\%CI 0.77-1.02, $p=0.09$ ). Elixhauser comorbidity scores, DNR status, and ascites were also predictors of fewer HFDs at 30-, 90-, and 180-days ( $p<0.0001$ all).

Table 4 presents the unadjusted and IPTW analyses of our secondary outcomes. Thirty-day complication rates were greater for surgical patients compared to medical patients $(44.0 \%$ vs. $21.3 \%$ unweighted, $p<0.0001)$. Additionally, surgical patients had longer lengths of stay for the index admission compared to medical patients (13 vs. 5 days unweighted, $p<0.0001$ ). However, 7 -day and 30-day readmissions were greater among medical patients compared to surgical patients $(15.2 \%$ vs. $10.9 \%$ unweighted, $p=0.0003$, and $34.5 \%$ vs. $23.4 \%$ unweighted, $p<0.0001$ respectively). Re-obstruction was more frequent among medically managed patients compared to surgical patients $(27.3 \%$ vs. $10.5 \%$ unweighted, $p<0.0001)$. Of those who underwent medical management, 9.5\% underwent an operation for re-obstruction within 1 year of the initial obstruction, whereas, only $2.2 \%$ of surgically managed patients underwent re-operation during a subsequent readmission for re-obstruction. Furthermore, time to first readmission and re-obstruction was shorter for medical patients (IPTW sub-hazard ratio (SHR) 0.72, 95\%CI 0.66-0.79, $\mathrm{p}<0.0001$ and IPTW SHR 0.33, 95\%CI $0.28-0.43, \mathrm{p}<0.0001$, respectively). Tests of statistical significance for these analyses were similar with and without IPTW. Figure 4a/b illustrates the unweighted and IPTW overall survival stratified by medical versus surgical management. Overall, there were no differences in survival between groups with and without IPTW $(p>0.05)$. Median survival was 6.4 months for medically managed patients and 6.5 months for surgically managed patients.

\section{Discussion}

In this population-based analysis of end-stage cancer patients with malignant bowel obstruction, medical management was associated with fewer in-hospital deaths and less hospital utilization, as defined by HFDs, at 30- and 90-days compared to surgical management. However, at 180-days, medical management and surgical management outcomes were comparable with respect to HFDs. Such findings were surprising, as they demonstrated that despite the increased rate of readmissions and re-obstruction associated with medical management described in this analysis and prior studies [4, 17], cumulative time hospitalized was less early on and persisted for at least 90 days for medical patients compared to surgical patients. These findings illustrate the complexity associated with palliative decision-making among $\mathrm{MBO}$ patients and the potential for surgery to negatively impact important quality-of-life related endpoints in these patients.

As the median survival after diagnosis of $\mathrm{MBO}$ was approximately 6 months in both cohorts, our data underscore the limited span for these patients and reinforce the concept that treatment recommendations must prioritize patient-centered care goals such as prolonged and repeated hospitalizations and avoidance of therapeutic morbidity. Prior research has shown that end-of-life care at home is preferred by patients and caregivers [20, 37, 38]. For example, in a survey of Medicare beneficiaries, Barnato et al. reported that $86 \%$ of Medicare patients expressed a preference for spending their time at home at the end-of-life [37]. Similarly, in-hospital and ICU deaths among end-stage cancer patients have been associated with worse patient quality of life and greater caregiver emotional distress [38]. Therefore, the greater risk of in-hospital death and fewer HFDs at 30- and 90-days observed in our study among surgical patients appears to be clinically significant and may help guide evolving multidisciplinary palliative care recommendations for patients diagnosed with $\mathrm{MBO}$. Additionally, our finding of a median survival of 6 months among $\mathrm{MBO}$ patients further highlights that the diagnosis of $\mathrm{MBO}$ is a pre-terminal event for most patients requiring advanced care planning and thoughtful goals of care discussions at the time of diagnosis, if not earlier.

This population-based analysis of $\mathrm{MBO}$ patients addresses an important gap in previous research. In contrast with prior studies, our patient cohort consisted of both elderly and non-elderly patients with a variety of 
Table 3 Univariate (Model 1) and multivariate (Model 2) inverse probability to treatment weighted regression models for ${ }^{\mathrm{a}}$ fewer hospital-free days at 30, 90 and 180 days

\begin{tabular}{|c|c|c|c|c|c|c|c|c|c|c|c|c|}
\hline & \multicolumn{4}{|c|}{ 30-Day Hospital-Free Days } & \multicolumn{4}{|c|}{ 90-Day Hospital Free Days } & \multicolumn{4}{|c|}{ 180-Day Hospital Free Days } \\
\hline & $\mathrm{OR}$ & \multicolumn{2}{|c|}{$95 \% \mathrm{Cl}$} & \multirow[t]{2}{*}{$P$ value } & \multirow[t]{2}{*}{$\mathrm{OR}$} & \multicolumn{2}{|c|}{$95 \% \mathrm{Cl}$} & \multirow[t]{2}{*}{$P$ value } & \multirow[t]{2}{*}{$\mathrm{OR}$} & \multicolumn{2}{|c|}{$95 \% \mathrm{Cl}$} & \multirow[t]{2}{*}{$P$ value } \\
\hline & & & & & & \multicolumn{4}{|c|}{ Model 1} & & & \\
\hline \multicolumn{13}{|l|}{ Treatment } \\
\hline \multicolumn{13}{|l|}{ Medical (ref) } \\
\hline Surgery & 3.98 & 3.40 & 4.67 & $<0.0001$ & 1.24 & 1.08 & 1.42 & 0.004 & 0.89 & 0.77 & 1.02 & 0.09 \\
\hline \multicolumn{13}{|l|}{ Model 2} \\
\hline \multicolumn{13}{|l|}{ Treatment } \\
\hline \multicolumn{13}{|l|}{ Medical (ref) } \\
\hline Surgery & 4.54 & 3.86 & 5.34 & $<0.0001$ & 1.26 & 1.09 & 1.46 & 0.002 & 0.87 & 0.75 & 1.01 & 0.06 \\
\hline Age & 1.00 & 0.99 & 1.01 & 0.97 & 1.00 & 1.00 & 1.01 & 0.65 & 1.01 & 1.00 & 1.01 & 0.08 \\
\hline \multicolumn{13}{|l|}{ Gender } \\
\hline \multicolumn{13}{|l|}{ Female (ref) } \\
\hline Male & 1.07 & 0.90 & 1.28 & 0.45 & 1.09 & 0.93 & 1.29 & 0.30 & 1.14 & 0.97 & 1.34 & 0.13 \\
\hline \multicolumn{13}{|l|}{ Race/Ethnicity } \\
\hline \multicolumn{13}{|l|}{ Caucasian (ref) } \\
\hline Asian/Pacific Islander & 0.94 & 0.73 & 1.21 & 0.64 & 1.01 & 0.80 & 1.27 & 0.94 & 1.05 & 0.83 & 1.32 & 0.69 \\
\hline Black & 1.90 & 1.44 & 2.49 & $<0.0001$ & 1.37 & 1.03 & 1.84 & 0.03 & 1.22 & 0.91 & 1.62 & 0.18 \\
\hline Hispanic & 0.92 & 0.73 & 1.17 & 0.51 & 1.07 & 0.86 & 1.34 & 0.53 & 1.13 & 0.91 & 1.40 & 0.28 \\
\hline Other/Unknown & 1.13 & 0.67 & 1.91 & 0.66 & 0.90 & 0.56 & 1.43 & 0.65 & 0.70 & 0.45 & 1.09 & 0.11 \\
\hline Elixhauser Comorbidity & 1.06 & 1.05 & 1.07 & $<0.0001$ & 1.04 & 1.03 & 1.05 & $<0.0001$ & 1.04 & 1.03 & 1.05 & $<0.0001$ \\
\hline DNR Status & 1.95 & 1.50 & 2.54 & $<0.0001$ & 2.37 & 1.82 & 3.07 & $<0.0001$ & 2.60 & 1.99 & 3.38 & $<0.0001$ \\
\hline Ascites & 2.04 & 1.62 & 2.56 & $<0.0001$ & 2.38 & 1.91 & 2.97 & $<0.0001$ & 2.19 & 1.75 & 2.75 & $<0.0001$ \\
\hline \multicolumn{13}{|l|}{ Cancer Diagnosis } \\
\hline \multicolumn{13}{|l|}{ Colorectal (ref) } \\
\hline Ovarian & 0.79 & 0.61 & 1.04 & 0.09 & 0.71 & 0.55 & 0.92 & 0.01 & 0.76 & 0.59 & 0.99 & 0.04 \\
\hline Pancreatic & 1.37 & 0.89 & 2.12 & 0.16 & 1.65 & 1.09 & 2.50 & 0.02 & 2.24 & 1.48 & 3.39 & 0.0001 \\
\hline Hepatobiliary & 1.02 & 0.42 & 2.46 & 0.97 & 1.86 & 0.79 & 4.40 & 0.16 & 1.66 & 0.80 & 3.44 & 0.17 \\
\hline Foregut \& Small Bowel & 1.03 & 0.65 & 1.62 & 0.91 & 1.46 & 0.96 & 2.22 & 0.07 & 2.23 & 1.48 & 3.35 & 0.0001 \\
\hline Nonovarian Urogyn & 1.37 & 1.00 & 1.87 & 0.05 & 1.63 & 1.21 & 2.19 & 0.001 & 1.90 & 1.11 & 3.25 & 0.02 \\
\hline Lung/Mediastinal & 0.93 & 0.51 & 1.70 & 0.81 & 1.27 & 0.74 & 2.17 & 0.38 & 2.11 & 1.56 & 2.88 & $<0.0001$ \\
\hline Other & 0.97 & 0.69 & 1.36 & 0.84 & 0.75 & 0.55 & 1.03 & 0.07 & 1.06 & 0.77 & 1.45 & 0.73 \\
\hline Unknown & 0.82 & 0.65 & 1.04 & 0.10 & 0.84 & 0.67 & 1.05 & 0.12 & 0.91 & 0.73 & 1.14 & 0.41 \\
\hline Multiple Diagnoses & 0.99 & 0.77 & 1.27 & 0.95 & 1.22 & 0.96 & 1.54 & 0.10 & 1.29 & 1.02 & 1.63 & 0.04 \\
\hline
\end{tabular}

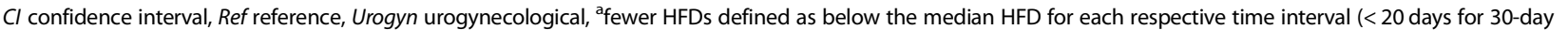
HFDs, $<70$ days for 90-day HFDs, and $<133$ for 180 -day HFDs)

primary cancer diagnoses receiving care at more than 500 hospitals (although admittedly limited California), thereby, contributing to the generalizability of our findings. Additionally, we attempted to account for selection bias by using propensity score IPTW based on measured patient demographic and clinical characteristics, creating a similar distribution of each covariate for medical and surgical patients $[36,39]$. We do acknowledge the potential implications of unmeasured confounders, including severity of obstruction and patient and physician preferences, and as such, considered instrumental variable analyses as an alternative approach. Unfortunately, due to absence of an 'instrumental variable' (i.e. variable associated with the treatment, but not directly associated with the primary outcome), such an approach was not possible. Regardless, our adjustment of known confounders is a well-validated methodology to control for potential selection bias within the limitations of a retrospective dataset. 
Table 4 Length of stay, complications, readmissions, emergency department visits, and re-obstruction for medical and surgical malignant bowel obstruction patients

\begin{tabular}{|c|c|c|c|c|c|c|c|c|}
\hline \multirow[b]{3}{*}{ Length of stay (median, IQR) } & \multicolumn{2}{|c|}{ Medical Management } & \multicolumn{2}{|c|}{ Surgical Management } & \multicolumn{3}{|c|}{ Adjusted Odds Ratios $^{a}$} & \multirow[t]{2}{*}{$P$-value } \\
\hline & \multirow{2}{*}{$\begin{array}{l}\mathrm{N} \\
5(3-8)\end{array}$} & \multirow[t]{2}{*}{$\%$} & \multirow{2}{*}{$\frac{N}{13(9-20)}$} & \multirow[t]{2}{*}{$\%$} & \multirow{2}{*}{$\frac{\mathrm{OR}}{0.91^{\mathrm{b}}}$} & \multicolumn{2}{|c|}{$95 \% \mathrm{Cl}$} & \\
\hline & & & & & & $0.87^{b}$ & $0.95^{\mathrm{b}}$ & $<0.0001$ \\
\hline 30-day complications & 727 & $21.3 \%$ & 508 & $44.0 \%$ & 2.37 & 2.04 & 2.75 & $<0.0001$ \\
\hline \multicolumn{9}{|l|}{$\underline{\text { Readmissions }}^{c}$} \\
\hline 7-day & 495 & $15.2 \%$ & 111 & $10.9 \%$ & 0.64 & 0.51 & 0.80 & 0.0001 \\
\hline 30-day & 1133 & $34.5 \%$ & 244 & $23.4 \%$ & 0.56 & 0.48 & 0.67 & $<0.0001$ \\
\hline \multicolumn{9}{|l|}{${\underline{E D} \text { visits }^{c}}$} \\
\hline 7-day & 149 & $4.5 \%$ & 50 & $4.8 \%$ & 1.05 & 0.74 & 1.48 & 0.80 \\
\hline 30-day & 384 & $11.7 \%$ & 120 & $11.5 \%$ & 1.00 & 0.79 & 1.25 & 0.98 \\
\hline Re-obstruction within 1 year ${ }^{c}$ & 897 & $27.3 \%$ & 110 & $10.5 \%$ & 0.33 & 0.26 & 0.41 & $<0.0001$ \\
\hline
\end{tabular}

$E D$ emergency department, $\mathrm{Cl}$ confidence interval

${ }^{a}$ Odds ratio (except for length of stay which is the regression coefficient) for surgery with medical management treated as reference and adjusted with inverse probability of treatment weighted (IPTW) analyses using propensity scores created from: age, race, gender, cancer diagnoses, presence of ascites, Elixhuaser comorbidity index score, and DNR status

${ }^{\mathrm{b}}$ Regression coefficient for log-transformed LOS adjusted with IPTW; with retransformation, indicates a 2.5 -fold increase in LOS for surgical patients

cexcluding patients who died at date of discharge $(N=4327)$, ED visits not associated with hospital admission

Our novel study design, including large sample size, likely contributes to the key findings we observed in our analysis, particularly with respect to prior studies. For example, although in-hospital death and disposition to home were shown to be equivalent for medical and surgical management of $\mathrm{MBO}$ in a single institution retrospective study by Henry et al., we observed a significantly greater risk of in-hospital death and disposition to a facility after surgical management of MBO [17]. Additionally, although small single-institution retrospective studies of $\mathrm{MBO}$ have observed greater survival for surgical patients with reported increases in median survival ranging from 2 to 5 months, we and population-based studies consisting of elderly cohorts have shown equivalent survival between medical and surgical patients [3-5, 17, 40, 41]. Such differences reflect the value of using population-based data to investigate these challenging clinical problems.

Despite the strengths of our study and the clinically meaningful findings, it is nevertheless important to acknowledge potential limitations and implications for future research. Although we used IPTW to adjust for key measured confounding factors, we were not able to obtain data on and adjust for important clinical patient and disease characteristics including cancer burden, performance status, severity or location of bowel obstruction, as well as surgeon and patient preferences and hospital-level variation. This is a current limitation of administrative databases, including OSHPD. Moreover, we were not able to evaluate differences in symptomatic relief (i.e. restoration of diet and pain) or directly assess quality of life following medical versus surgical treatment. The few studies comparing symptom relief with medical versus surgical management of
MBO presently consist of single-institution cohorts $[17$, 41]. Although each of these studies found equivalent rates of symptom resolution, more research is needed to better understand these questions. Furthermore, we did not separately evaluate patients who underwent procedural interventions for $\mathrm{MBO}$ (such as colonic stenting or percutaneous gastrostomy tube). Although there has been research demonstrating improved outcomes in patients undergoing procedural management compared to surgical management $[4,42]$, there were notably few patients in our dataset who underwent these procedures alone, so the impact of this limited number of patients on our results is likely to be minimal. However, in patient cohorts where interventional and endoscopic management of $\mathrm{MBO}$ is more prevalent, the effect of these procedures on outcomes warrants further detailed evaluation. Lastly, we recognize MBO patients are a heterogenous cohort with a range of clinical severity and rate of cancer progression. This is exemplified in the approximately $20 \%$ of patients with relatively long-term survival (see Figs. 4a/b). As such, future research should assess whether patients with longer survival times after a diagnosis of MBO derive greater benefit from surgical management given the potential for some patients in this analysis to live longer and the equalization of HFD by 180 days post index MBO diagnosis [43].

\section{Conclusions}

Ultimately, in this population-based analysis, medical management of MBO was associated with fewer in-hospital deaths, greater discharges to home, and more 


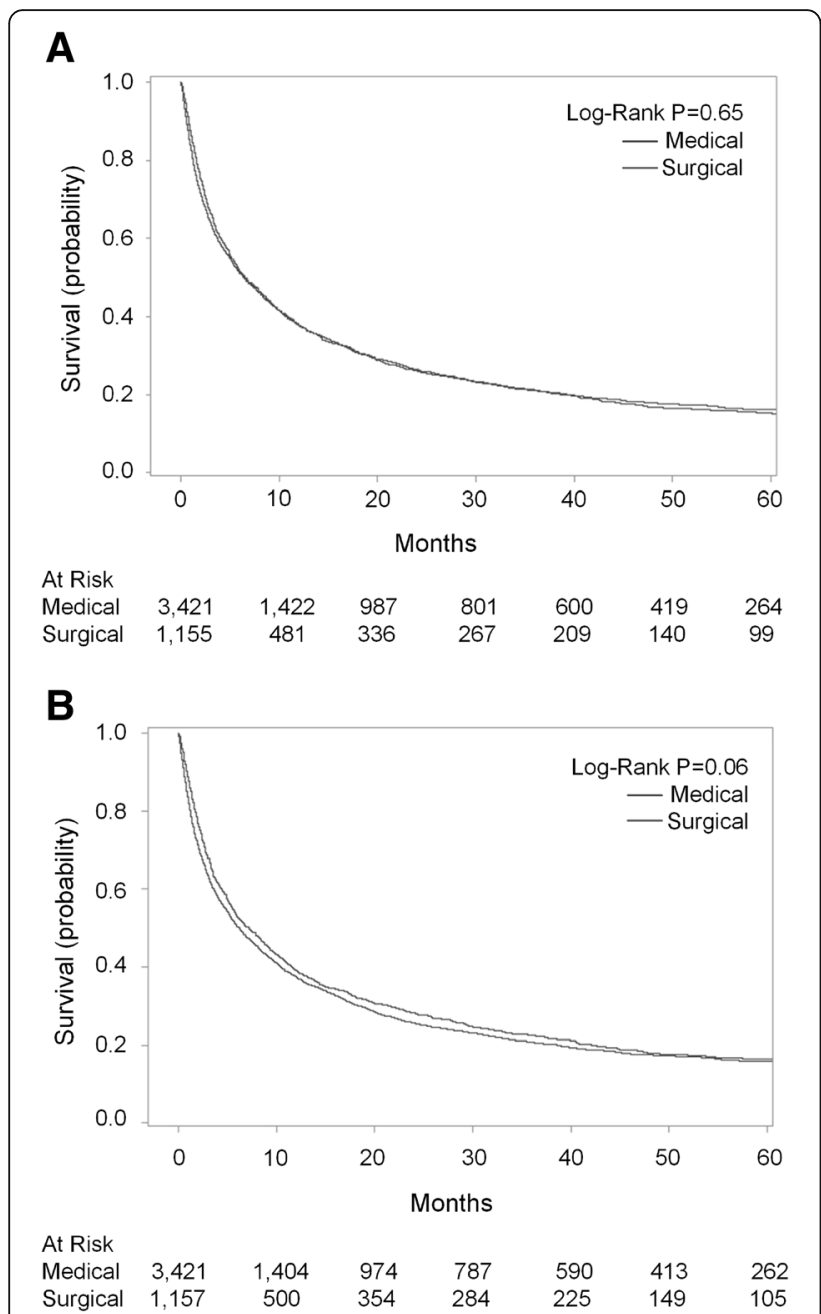

Fig. $4(\mathbf{a} / \mathbf{b})$ Unadjusted (a) and inverse probability to treatment weighted (b) overall survival for patients hospitalized with malignant bowel obstruction treated with medical and surgical management

HFDs at 30- and 90-days with equivalent survival to surgical management. These data highlight the potential benefits of medical management of $\mathrm{MBO}$ in advanced cancer patients and warrant careful consideration, including whether surgery is indicated, when determining end-of-life treatment goals in this vulnerable patient population.

\section{Additional files}

Additional file 1: Table S1. International Classification of Diseases 9th edition (ICD-9) codes used for identification of malignant bowel obstruction patient diagnoses and surgical treatment. (DOCX $17 \mathrm{~kb}$ )

\section{Abbreviations}

Cl: Confidence interval; ED: Emergency department; EDD: Emergency department; HFDs: Hospital-free days; IPTW: Inverse probability of treatment weighting; IQR: Interquartile range; MBO: Malignant bowel obstruction; OSHPD: Office of Statewide Health Planning and Development; PDD: Patient discharge; SD: Standard deviation; SNF: Skilled nursing facility

\section{Acknowledgements}

Not applicable.

\section{Author contributions}

Conception (SBB, RJC, AAG, FJM, RJB, SLS), data curation (SBB, RJC), analysis (SBB, SLS), funding (RJC), methodology (SBB, SLS, RJC, FJM, RJB, AAG), writing original draft/revisions (SBB, RJC, RJB, FJM, SLS, AAG). All authors read and approved the final manuscript.

\section{Funding}

This project was supported by the National Center for Advancing Translational Sciences, NIH (UL1TR001860), the Agency for Health Care Research and Quality (T32HS022236), and the University of California Cancer Research Coordinating Committee (RJC, CTR\#-18-524770). The content is solely the responsibility of the authors and does not necessarily represent the official views of the NIH. All funding bodies did not participate and are not responsible for the study design, data collection, analysis, data interpretation and writing of the manuscript.

\section{Availability of data and materials}

The data that support the findings of this study are available from the California Office of Statewide Health Planning and Development (OSHPD) but restrictions apply to the availability of these data, which were used under data use agreement for the current study, and so are not publicly available. Data are however available from the authors upon reasonable request and with permission of OSHPD and the California Department of Public Health.

\section{Ethics approval and consent to participate}

The research protocol described in this manuscript was reviewed and approved by the University of California Davis Institutional Review Board, the California Department of Public Health, and the California Office of Statewide Health Planning and Development. (OSHPD). We were granted a waiver of consent by these institutions due to the retrospective nature of the study and as all patient data was de-identified, it was therefore not possible to obtain patient consent.

\section{Consent for publication}

Not applicable.

\section{Competing interests}

The authors declare that they have no competing interests.

\section{Publisher's Note}

Springer Nature remains neutral with regard to jurisdictional claims in published maps and institutional affiliations.

\section{Author details}

'Division of Surgical Oncology, UC Davis Cancer Center, 4501 X Street, Suite 3010, Sacramento, CA 95817, USA. ²Department of Public Health Sciences, Division of Biostatistics, UC Davis School of Medicine, 4800 2nd Ave, Suite 2209, Sacramento, CA 95817, USA. "3Division of Hematology/Oncology, Department of Internal Medicine, UC Davis Medical Center, 4610 X Street, Suite 3016, Sacramento, CA 95817, USA.

Received: 26 July 2018 Accepted: 19 November 2018 Published online: 26 November 2018

\section{References}

1. Cousins SE, Tempest E, Feuer DJ. Surgery for the resolution of symptoms in malignant bowel obstruction in advanced gynaecological and gastrointestinal cancer. Cochrane Database Syst Rev. 2016;1:CD002764.

2. Chakraborty A, Selby D, Gardiner K, Myers J, Moravan V, Wright F. Malignant bowel obstruction: natural history of a heterogeneous patient population followed prospectively over two years. J Pain Symptom Manag. 2011;41(2): $412-20$.

3. Mooney SJ, Winner M, Hershman DL, Wright JD, Feingold DL, Allendorf JD, et al. Bowel obstruction in elderly ovarian cancer patients: a populationbased study. Gynecol Oncol. 2013;129(1):107-12.

4. Lilley EJ, Scott JW, Goldberg JE, Cauley CE, Temel JS, Epstein AS, et al. Survival, healthcare utilization, and end-of-life care among older adults with malignancy-associated bowel obstruction: comparative study of surgery, venting gastrostomy, or medical management. Ann Surg. 2017;267(4):692-9. 
5. Winner M, Mooney SJ, Hershman DL, Feingold DL, Allendorf JD, Wright JD, et al. Management and outcomes of bowel obstruction in patients with stage IV colon cancer: a population-based cohort study. Dis Colon Rectum. 2013;56(7):834-43.

6. Paul Olson TJ, Pinkerton C, Brasel KJ, Schwarze ML. Palliative surgery for malignant bowel obstruction from carcinomatosis: a systematic review. JAMA Surg. 2014;149(4):383-92.

7. Tseng WH, Yang X, Wang H, Martinez SR, Chen SL, Meyers FJ, et al. Nomogram to predict risk of 30-day morbidity and mortality for patients with disseminated malignancy undergoing surgical intervention. Ann Surg. 2011;254(2):333-8.

8. Bateni SB, Meyers FJ, Bold RJ, Canter RJ. Current perioperative outcomes for patients with disseminated cancer. J Surg Res. 2015;197(1):118-25.

9. Bateni SB, Meyers FJ, Bold RJ, Canter RJ. Increased rates of prolonged length of stay, readmissions, and discharge to care facilities among postoperative patients with disseminated malignancy: implications for clinical practice. PLoS One. 2016;11(10):e0165315.

10. Bateni SB, Bold RJ, Meyers FJ, Canter DJ, Canter RJ. Comparison of common risk stratification indices to predict outcomes among stage IV cancer patients with bowel obstruction undergoing surgery. J Surg Oncol. 2017; 117(3):479-87.

11. Pothuri B, Vaidya A, Aghajanian C, Venkatraman E, Barakat RR, Chi DS. Palliative surgery for bowel obstruction in recurrent ovarian cancer:an updated series. Gynecol Oncol. 2003;89(2):306-13.

12. Chi DS, Phaeton R, Miner TJ, Kardos SV, Diaz JP, Leitao MM Jr, et al. A prospective outcomes analysis of palliative procedures performed for malignant intestinal obstruction due to recurrent ovarian cancer. Oncologist. 2009;14(8):835-9.

13. Network NCC. NCCN clinical practice guidelines in oncology. Palliative Care. 2018.

14. Laval G, Marcelin-Benazech B, Guirimand F, Chauvenet L, Copel L, Durand A, et al. Recommendations for bowel obstruction with peritoneal carcinomatosis. J Pain Symptom Manag. 2014;48(1):75-91.

15. Bateni SB, Canter RJ, Meyers FJ, Galante JM, Bold RJ. Palliative care training and decision-making for patients with advanced Cancer: a comparison of surgeons and medical physicians. Surgery. 2018;S0039-6060(18):30078-3.

16. Verrees JF, Fernandez-Trigo V, Sugarbaker PH. Rectal cancer recurrence after prior resection and radiotherapy: palliation following additional surgery. Int J Color Dis. 1996;11(5):211-6.

17. Henry JC, Pouly S, Sullivan R, Sharif S, Klemanski D, Abdel-Misih S, et al. A scoring system for the prognosis and treatment of malignant bowel obstruction. Surgery. 2012;152(4):747-56 discussion 56-7.

18. Lilley EJ, Cooper Z, Schwarze ML, Mosenthal AC. Palliative Care in Surgery: defining the research priorities. Ann Surg. 2017;267(1):66-72.

19. Gerrard R, Campbell J, Minton O, Moback B, Skinner C, McGowan C, et al. Achieving the preferred place of care for hospitalized patients at the end of life. Palliat Med. 2011;25(4):333-6.

20. Higginson IJ, Sen-Gupta GJ. Place of care in advanced cancer: a qualitative systematic literature review of patient preferences. J Palliat Med. 2000;3(3): 287-300.

21. Gabler NB, Cooney E, Small DS, Troxel AB, Arnold RM, White DB, et al. Default options in advance directives: study protocol for a randomised clinical trial. BMJ Open. 2016;6(6):e010628.

22. Whitney RL, Bell JF, Tancredi DJ, Romano PS, Bold RJ, Joseph JG. Hospitalization rates and predictors of Rehospitalization among individuals with advanced Cancer in the year after diagnosis. J Clin Oncol. 2017;35(31):3610-7.

23. Yermilov I, Bentrem D, Sekeris E, Jain S, Maggard MA, Ko CY, et al. Read missions following pancreaticoduodenectomy for pancreas cancer: a population-based appraisal. Ann Surg Oncol. 2009;16(3):554-61.

24. Kruper $L, X u X$, Henderson $K$, Bernstein L. Disparities in reconstruction rates after mastectomy for ductal carcinoma in situ (DCIS): patterns of care and factors associated with the use of breast reconstruction for DCIS compared with invasive cancer. Ann Surg Oncol. 2011;18(11):3210-9.

25. Brooke BS, Meguid RA, Makary MA, Perler BA, Pronovost PJ, Pawlik TM. Improving surgical outcomes through adoption of evidence-based process measures: intervention specific or associated with overall hospital quality? Surgery. 2010;147(4):481-90.

26. Alese OB, Kim S, Chen Z, Owonikoko TK, El-Rayes BF. Management patterns and predictors of mortality among US patients with cancer hospitalized for malignant bowel obstruction. Cancer. 2015;121(11):1772-8.
27. Moore BJ, White S, Washington R, Coenen N, Elixhauser A. Identifying increased risk of readmission and in-hospital mortality using hospital administrative data: the AHRQ Elixhauser comorbidity index. Med Care. 2017:55(7):698-705.

28. van Walraven C, Austin PC, Jennings A, Quan H, Forster AJ. A modification of the Elixhauser comorbidity measures into a point system for hospital death using administrative data. Med Care. 2009;47(6):626-33.

29. Quan H, Sundararajan V, Halfon P, Fong A, Burnand B, Luthi JC, et al. Coding algorithms for defining comorbidities in ICD-9-CM and ICD-10 administrative data. Med Care. 2005;43(11):1130-9.

30. Elixhauser A, Steiner C, Harris DR, Coffey RM. Comorbidity measures for use with administrative data. Med Care. 1998;36(1):8-27.

31. Cullinane CA, Borneman T, Smith DD, Chu DZ, Ferrell BR, Wagman LD. The surgical treatment of cancer: a comparison of resource utilization following procedures performed with a curative and palliative intent. Cancer. 2003; 98(10):2266-73.

32. Weingart SN, lezzoni LI, Davis RB, Palmer RH, Cahalane M, Hamel MB, et al. Use of administrative data to find substandard care: validation of the complications screening program. Med Care. 2000;38(8):796-806.

33. lezzoni LI, Daley J, Heeren T, Foley SM, Fisher ES, Duncan C, et al. Identifying complications of care using administrative data. Med Care. 1994;32(7):700-15

34. Ghaferi AA, Birkmeyer JD, Dimick JB. Complications, failure to rescue, and mortality with major inpatient surgery in medicare patients. Ann Surg. 2009; 250(6):1029-34.

35. Garrido MM, Kelley AS, Paris J, Roza K, Meier DE, Morrison RS, et al. Methods for constructing and assessing propensity scores. Health Serv Res. 2014; 49(5):1701-20.

36. Austin PC. An introduction to propensity score methods for reducing the effects of confounding in observational studies. Multivariate Behav Res. 2011;46(3):399-424.

37. Barnato AE, Herndon MB, Anthony DL, Gallagher PM, Skinner JS, Bynum JP, et al. Are regional variations in end-of-life care intensity explained by patient preferences?: a study of the US Medicare population. Med Care. 2007;45(5):386-93.

38. Wright AA, Keating NL, Balboni TA, Matulonis UA, Block SD, Prigerson HG. Place of death: correlations with quality of life of patients with cancer and predictors of bereaved caregivers' mental health. J Clin Oncol. 2010;28(29): 4457-64.

39. Vansteelandt S, Daniel RM. On regression adjustment for the propensity score. Stat Med. 2014;33(23):4053-72.

40. Goto T, Takano M, Aoyama T, Miyamoto M, Watanabe A, Kato M, et al. Outcomes of palliative bowel surgery for malignant bowel obstruction in patients with gynecological malignancy. Oncol Lett. 2012;4(5):883-8.

41. Mangili G, Aletti G, Frigerio L, Franchi M, Panacci N, Vigano R, et al. Palliative care for intestinal obstruction in recurrent ovarian cancer: a multivariate analysis. Int J Gynecol Cancer. 2005;15(5):830-5.

42. Abelson JS, Yeo HL, Mao J, Milsom JW, Sedrakyan A. Long-term Postprocedural outcomes of palliative emergency stenting vs stoma in malignant large-bowel obstruction. JAMA Surg. 2017;152(5):429-35.

43. Helyer LK, Law CHL, Butler M, Last LD, Smith AJ, Wright FC. Surgery as a bridge to palliative chemotherapy in patients with malignant bowel obstruction from colorectal Cancer. Ann Surg Oncol. 2007;43(6):1264-71.

\section{Ready to submit your research? Choose BMC and benefit from:}

- fast, convenient online submission

- thorough peer review by experienced researchers in your field

- rapid publication on acceptance

- support for research data, including large and complex data types

- gold Open Access which fosters wider collaboration and increased citations

- maximum visibility for your research: over $100 \mathrm{M}$ website views per year

At $\mathrm{BMC}$, research is always in progress.

Learn more biomedcentral.com/submissions 